\title{
Umidade e congelamento de grãos de amaranto e sua capacidade de expansão térmica
}

\author{
Maria das Graças de Assis Bianchini(1) e Adelaide Del Pino Beléia(2)
}

(1)Universidade Federal de Mato Grosso, Faculdade de Nutrição, Avenida Fernando Correia da Costa no 2367, CEP 78060-900 Cuiabá, MT. E-mail: magra@ufmt.br (2)Universidade Estadual de Londrina, Departamento de Ciência e Tecnologia de Alimentos, Caixa Postal 6001, CEP 86051-980 Londrina, PR. E-mail: beleia@uel.br

Resumo - O objetivo deste trabalho foi avaliar a influência do teor de umidade, da temperatura de armazenamento e do momento da hidratação de grãos de amaranto (Amaranthus cruentus L.) sobre sua capacidade de expansão térmica, bem como comparar as composições químicas de grãos crus e pipocados. Os atributos diâmetro médio ponderado, volume de expansão, densidade, rendimento, quantidade descartada e tempo de residência de grãos da variedade BRS Alegria foram avaliados de acordo com três teores de umidade $(9,5,11,5$ e $13,5 \%)$, duas formas de armazenamento, temperatura ambiente de $\pm 28^{\circ} \mathrm{C}$ e congelado a $-18^{\circ} \mathrm{C}$, e dois momentos de hidratação, antes e após congelamento. Utilizou-se chapa metálica aquecida a $215^{\circ} \mathrm{C}$ para pipocar os grãos. Grãos congelados com umidade de 13,5\% tiveram maior diâmetro médio ponderado e volume de expansão, e menor densidade e tempo de residência. A umidade de 13,5\% proporcionou os maiores rendimentos e expansão dos grãos. $\mathrm{O}$ armazenamento a $-18^{\circ} \mathrm{C}$ produziu pipocas maiores e mais leves do que em condições ambientais. As pipocas apresentaram redução nos teores de proteínas e fibras insolúveis e aumento nos de lipídeos e fibras solúveis, em relação ao grão cru. $\mathrm{O}$ congelamento dos grãos a $-18^{\circ} \mathrm{C}$ e sua hidratação a 13,5\% de umidade favorecem o pipocamento de grãos de amaranto, com produção de pipocas de melhor qualidade.

Termos para indexação: Amaranthus cruentus, composição química, pipocamento, propriedades físicas.

\section{Moisture and freezing of amaranth grains and their thermal expansion capacity}

\begin{abstract}
The objective of this work was to evaluate the influence of moisture content, storage temperature, and moment of hydration of amaranth (Amaranthus cruentus L.) grains on their expansion capacity, as well to compare the chemical compositions of raw and popped grain. The attributes mean weight diameter, volume of expansion, density, yield, amount of non popped grains and residence time of BRS Alegria grains were evaluated according to three grain moisture contents $(9.5,11.5$ and $13.5 \%)$, two forms of storage, environment temperature $\left( \pm 28^{\circ} \mathrm{C}\right)$ and freezing $\left(-18^{\circ} \mathrm{C}\right)$, and two different stages of hydration, before and after freezing. A metal plate was heated to $215^{\circ} \mathrm{C}$ to pop the grains. Frozen grains with $13.5 \%$ moisture content had higher average diameter and volume expansion, lower density and residence time. The grain moisture content of $13.5 \%$ produced the highest yields and grain expansions. The storage at $-18^{\circ} \mathrm{C}$ provided larger and lighter popping than the environmental one. Popping presented reduced protein and insoluble fibers and increased lipid and soluble fiber in relation to the raw grain. Frozen grains at $-18^{\circ} \mathrm{C}$ and hydration at $13.5 \%$ moisture, favors the popping of amaranth, and results in higher quality of the popped grains.
\end{abstract}

Index terms: Amaranthus cruentus, chemical composition, popping, physical properties.

\section{Introdução}

O amaranto (Amaranthus cruentus L.) é um pseudocereal com características agronômicas, nutricionais e funcionais que despertam interesse. Por apresentar crescimento rápido e ser capaz de se desenvolver e frutificarem ambientes comluminosidade intensa, alta temperatura e restrição hídrica, o amaranto tornou-se uma ótima opção para cultivo no Cerrado brasileiro (Spehar et al., 2003).

O grão de amaranto possui valor calórico e conteúdo de proteínas, lipídeos, fibras e minerais mais elevados do que a maioria dos cereais. De acordo com relatos em estudos recentes, vem sendo considerado um alimento funcional em razão de sua capacidade de reduzir os níveis de colesterol no sangue (Amaya-Farfan 
et al., 2005; Ferreira et al., 2007; Mendonça et al., 2009). Os grãos do amaranto têm sido incorporados em diferentes preparações para melhorar o valor nutricional e estimular o seu consumo. Ele pode ser consumido inteiro, cozido ou expandido, ou ainda na forma de farinhas, como substituto parcial ou integral da farinha de trigo na produção de pães, massas, bolos, ou na fabricação de barrinhas de cereais e "snacks" (Costa \& Borges, 2005; Marcílio et al., 2005; Capriles et al., 2006; Bodroza-Solarov et al., 2008).

O pipocamento é a maneira mais fácil de processamento dos grãos de amaranto, além resultar em um produto final de sabor agradável (Bressani et al., 1992). A literatura apresenta vários métodos de pipocamento de grãos de amaranto, desde o convencional, que usa chapa metálica quente, passando pelo fluxo de ar quente, vapor superaquecido em sistema de leito fluidizado, até o uso de extrusoras adaptadas (Singhal \& Kulkarni, 1991; Tovar et al., 1994; Tosi et al., 1996; Tikekar \& Karwe, 2009).

O mecanismo de expansão do grão de amaranto foi explicado por Tovar et al. (1994) e por Berghofer \& Schoenlechner (2002), e é muito semelhante ao do milho-pipoca. Durante o pipocamento, ocorre mudança de estado da água, de líquido para vapor, em um curto espaço de tempo, o que causa expansão. $O$ vapor interno cozinha, parcialmente, os diferentes tecidos do grão, principalmente o perisperma, o que causa a expansão dos grânulos de amido, a desnaturação das proteínas de reserva e a ruptura da casca dos grãos.

A habilidade de pipocar dos grãos de amaranto está relacionada, segundo Tovar et al. (1994), com o processo utilizado para pipocar, com a variedade e com o teor de umidade dos grãos. A influência do teor de umidade no pipocamento foi estudada por vários autores, entre eles Lara \& Ruales (2002), Konishi et al. (2004) e Zapotoczny et al. (2006), que trabalharam com umidades de grãos entre 12 e $30 \%$.

De modo geral, grãos podem ser armazenados a baixas temperaturas, e até mesmo sob congelamento, para prolongar seu tempo de prateleira. No entanto, segundo Damodaran et al. (2008), o congelamento altera a estrutura celular dos vegetais, e produz migrações de moléculas de água de sua localidade normal para os sítios de cristalização, o que resulta em aumento da tensão interna, e leva à separação de células, colapso e ruptura da parede celular. Essas alterações são percebidas, especialmente, no descongelamento.
No caso do amaranto, não foram localizados estudos para verificar se o congelamento interfere na capacidade de expansão dos grãos.

Este trabalho teve por objetivos examinar a influência do teor de umidade, da temperatura de armazenamento e do momento da hidratação dos grãos de $A$. cruentus, variedade BRS Alegria, sobre sua capacidade de expansão, e comparar as composições químicas dos grãos crus e das pipocas.

\section{Material e Métodos}

Utilizaram-se grãos da variedade BRS Alegria de amaranto, provenientes do Município de Sorriso, MT, Brasil. A área onde foi cultivado o amaranto localiza-se a $12^{\circ} 52^{\prime} \mathrm{S}$ e $55^{\circ} 32^{\prime} \mathrm{W}$, e altitude de $375 \mathrm{~m}$. O clima da região, segundo classificação de Köppen, é do tipo AWI. A temperatura média anual é de $26^{\circ} \mathrm{C}$, com médias em torno de $37^{\circ} \mathrm{C}$ no mês mais quente (outubro) e $15^{\circ} \mathrm{C}$ no mês mais frio (junho). A precipitação média anual está em torno de $2.233 \mathrm{~mm}$, concentrada no período de outubro a março, e a umidade relativa do ar média é de $80 \%$, mas de $22 \%$ no período entre junho e agosto. A semeadura do amaranto foi realizada em março e a colheita em junho de 2008. O cultivo foi realizado de acordo com as recomendações de Spehar \& Teixeira (2004).

Os grãos, após limpeza por sistema de ventilação, foram padronizados em peneira de 20 mesh, com abertura de $0,84 \mathrm{~mm}$, para remoção de matéria estranha e de grãos chochos. Os grãos padronizados foram secos em estufa, com circulação forçada de ar, à temperatura de $35 \pm 2^{\circ} \mathrm{C}$ até atingirem a umidade de $9,5 \%$.

Foram realizados dois experimentos independentes, ambos com delineamento inteiramente casualizado. No primeiro experimento, foram avaliados os efeitos de diferentes níveis de hidratação e do momento da hidratação sobre a capacidade de expansão térmica dos grãos. Utilizaram-se cinco tratamentos e nove repetições, como segue: grãos armazenados sob congelamento a $-18^{\circ} \mathrm{C}$, por 60 dias, com três diferentes teores de umidade $(9,5,11,5$ e $13,5 \%)$; e grãos armazenados sob congelamento a $-18^{\circ} \mathrm{C}$, com teor de umidade $9,5 \%$ e hidratados, pós descongelamento, para 11,5 ou $13,5 \%$. No segundo experimento, adotou-se o esquema fatorial com duas temperaturas de armazenamento $\left( \pm 28\right.$ e $\left.-18^{\circ} \mathrm{C}\right)$ e três teores de umidade $(9,5 ; 11,5$ e $13,5 \%)$, com dez repetições, para 
comparar o pipocamento de grãos congelados com os de não congelados, nos diferentes teores de umidade. Neste experimento os grãos foram hidratados antes do armazenamento a $-18^{\circ} \mathrm{C}$.

A hidratação dos grãos nos teores de umidade de $9 \%$ para 11 e 13,5\% foi efetuada com água destilada, com uso de nebulizador. Para promover boa redistribuição da água, os grãos hidratados foram acondicionados em recipientes hermeticamente fechados por 72 horas. Decorrido esse tempo, após confirmação do teor de umidade, os grãos foram acondicionados em embalagens de polietileno de $0,3 \mathrm{~mm}$ de espessura e submetidos aos tratamentos, conforme estabelecido nos dois experimentos.

O processo utilizado para a obtenção das pipocas de amaranto foi o convencional, com aquecimento em chapa metálica, sem adição de óleo e de temperos. O processo de pipocamento é influenciado, segundo Tovar et al. (1994), não só pela temperatura, mas também pelo tamanho do recipiente e pela quantidade de grãos utilizada em cada carga. Sendo assim, para se obter uniformidade nos tratamentos, padronizaramse as condições de processamento, de acordo com o rendimento e expansão dos grãos obtidos em ensaio prévio. As condições de processamento estabelecidas foram as seguintes: recipiente de alumínio com $142 \mathrm{~mm}$ de altura, $160 \mathrm{~mm}$ de diâmetro, $2 \mathrm{~mm}$ de espessura, e $4 \mathrm{~L}$ de volume; temperatura de pipocamento entre 215 e $220^{\circ} \mathrm{C}$, monitorada por termômetro digital dotado de sensor termopar tipo $\mathrm{K}$ e resolução de $0,1^{\circ} \mathrm{C}$; tamanho da amostra fixada em $10 \mathrm{~g}$ por ciclo. $\mathrm{O}$ tempo de residência foi monitorado por cronômetro com resolução de centésimos de segundo, e compreendeu o intervalo de tempo entre a deposição dos grãos no recipiente aquecido a $215^{\circ} \mathrm{C}$ e o término do pipocamento, detectado quando não mais se ouvia barulho de explosão.

As pipocas produzidas foram avaliadas quanto ao volume de expansão (VE), densidade, diâmetro médio ponderado (DMP), rendimento, tempo de residência e quantidade de grãos descartados (GD).

Uma peneira de malha $1,19 \mathrm{~mm}$ foi utilizada para separar os grãos pipocados dos não estourados. $\mathrm{O}$ volume de expansão (VE), a densidade e o rendimento foram obtidos de acordo com Delost-Lewis et al. (1992). O volume de expansão foi calculado pela razão entre o volume do grão estourado e o volume do peso equivalente de grãos crus. Para medir o volume dos grãos estourados, usou-se uma proveta de $100 \mathrm{~mL}$, com divisões de $1 \mathrm{~mL}$. A acomodação dos grãos dentro da proveta foi realizada com auxílio de um funil com posterior vibração, durante $1 \mathrm{~min}$, em um agitador horizontal, ajustado para a frequência de vibração de $3.600 \mathrm{~Hz}$, Produteste, (Telastem, São Paulo, Brasil). A seguir, o material foi medido e pesado. $\mathrm{O}$ volume do grão cru, de igual peso ao encontrado para o grão estourado, foi determinado em seguida. A densidade $\left(\mathrm{g} \mathrm{cm}^{-3}\right)$ foi obtida pela determinação da razão entre massa e volume dos grãos estourados. O rendimento, expresso em percentagem, foi obtido em função da massa dos grãos estourados e retidos na peneira $1,19 \mathrm{~mm}$, pela massa inicial dos grãos crus utilizados no processo.

Utilizou-se um conjunto de cinco peneiras, com malhas de 2,00, 1,68,1,41, 1,19 e 1,00 mm para determinação do DMP, que foi calculado com uso dos valores de diâmetro médio entre as peneiras e da massa de pipocas retida em cada peneira, conforme metodologia adaptada de Corrêa (2002). Foi usado um agitador horizontal, ajustado na frequência de vibração de $3.600 \mathrm{~Hz}$, Produteste, (Telastem, São Paulo, Brasil), durante dois min. A seguir, as massas das pipocas retidas em cada peneira foram determinadas e $\mathrm{o}$ diâmetro médio foi calculado. A quantidade de grãos a ser descartada (GD) foi obtida por meio de uma peneira com malha de 1,19 mm. Assim, todos os grãos que passaram pela peneira foram considerados descarte, $\mathrm{o}$ que abarcou, nessa categoria, os grãos não pipocados e aqueles que pipocaram mas não conseguiram expandir adequadamente.

A composição química dos grãos de amaranto crus e das pipocas de grãos congelados a $13,5 \%$ foi realizada em amostras moídas em pulverizador, (Fritsch $\mathrm{GmbH}$, Idar-Oberstein, Alemanha) com o rotor na velocidade de $12.000 \mathrm{rpm}$. Elas foram peneiradas em tamis de malha $0,420 \mathrm{~mm}$, embaladas em saco de polietileno com $0,3 \mathrm{~mm}$ de espessura e armazenadas a $-18^{\circ} \mathrm{C}$, até o momento da análise. $\mathrm{O}$ teor de umidade foi determinado pelo método número 012/IV do Instituto Adolfo Lutz (2005). As análises de cinzas, lipídeos e proteínas $(\mathrm{N} x$ 6,25) foram realizadas de acordo com a metodologia da AOAC International (1998), número 923-03, 920-39 e 960-52, respectivamente. Os carboidratos totais foram estimados por diferença, tendo-se subtraído de 100 a soma dos teores de cinzas, proteínas, lipídeos e umidade. As fibras insolúveis 
e solúveis foram determinadas pelo método 32-07 da AACC International (1999), com enzimas Sigma (Sigma-Aldrich, St Louis, EUA). A fibra total foi obtida pela soma da fibra insolúvel e a solúvel. Foram realizadas três repetições de cada análise.

Os dados obtidos foram avaliados por análise de variância, de correlação de Pearson e, para comparação de médias entre tratamentos, foi adotado o teste de Tukey, a $1 \%$ de probabilidade, tendo-se utilizado o aplicativo Minitab 13.1 (Minitab, 2005). $\mathrm{Na}$ composição centesimal, aplicou-se o teste $\mathrm{t}$ para dados não pareados, a $5 \%$ de probabilidade.

\section{Resultados e Discussão}

O momento da hidratação dos grãos não teve efeito sobre a densidade, volume de expansão, rendimento das pipocas e percentagem de grãos descartados (GD), em grãos hidratados a 11,5\% (Tabela 1). Em grãos hidratados a 13,5\% antes do congelamento, foram observados maiores valores de DMP, VE e menores de densidade e tempo de residência, em relação aos hidratados após congelamento. Esses resultados demonstram que o congelamento somente afetou a capacidade de expansão dos grãos, quando eles foram hidratados a $13,5 \%$ antes do congelamento, condição que possibilitou a maior expansão dos grãos de amaranto.

A formação de cristais de gelo durante o congelamento pode provocar alterações nas estruturas internas dos grãos, como membranas e paredes celulares (Damodaran et al., 2008). Os grãos de amaranto podem ter sofrido essas alterações de forma a promover o rápido aumento da pressão interna de vapor d'água, o que facilita a expansão termoplástica do amido presente no perisperma, com produção de pipocas grandes e leves. A pressão de vapor d'água obtida no interior do grão durante o aquecimento depende não somente da quantidade de água, ou umidade presente no grão, como também da resistência e integridade da casca. Portanto, o teor de umidade e a resistência e integridade da casca são fatores determinantes para a capacidade de expansão dos grãos ao pipocarem.

Os grãos hidratados a 11,5 e $13,5 \%$ após o congelamento não apresentaram diferenças quanto aos atributos DMP, densidade, VE, tempo de residência (Tabela 1). Nesse caso, a quantidade de água presente nos grãos era pequena e os cristais formados durante o congelamento podem não ter sido suficientes para romper estruturas internas do grão a ponto de favorecer o pipocamento. Por sua vez, as pipocas dos grãos congelados a 13,5\% apresentaram DMP, VE e rendimento superiores, e densidade e GD inferiores aos dos congelados a 11,5\%. Esses resultados indicam que, na umidade de $13,5 \%$, os cristais formados foram suficientes para causar modificações nas estruturas internas dos grãos e favorecer o pipocamento.

Para se obter a mesma capacidade de expansão de grãos hidratados a $11,5 \%$, antes do congelamento, seria necessário maior teor de umidade nos grãos hidratados após o congelamento (Tabela 1), o que reforça a ideia de que a hidratação antes do congelamento favorece a expansão dos grãos de amaranto.

O tempo de residência foi influenciado apenas pelo momento da hidratação dos grãos, e os grãos hidratados antes do congelamento pipocaram mais rápido do que os hidratados após o congelamento (Tabela 1). As alterações ocorridas nos grãos hidratados antes do congelamento não só produziram pipocas maiores e menos densas como também reduziram o tempo de processamento. Já o rendimento e o GD, ao contrário, não foram afetados pelo momento da hidratação, mas foram afetados pelo teor de umidade do grão, de modo que, na umidade de $13,5 \%$, o rendimento

Tabela 1. Diâmetro médio ponderado (DMP), densidade, volume de expansão (VE), rendimento, tempo de residência e percentagem de grãos descartados (GD) de pipocas obtidas de grãos de Amaranthus cruentus, com umidade de 9,5\%, e de grãos hidratados a 11,5 e 13,5\%, antes e após congelamento ${ }^{(1)}$.

\begin{tabular}{lccccc}
\hline Tratamentos & DMP $(\mathrm{mm})$ & Densidade $\left(\mathrm{g} \mathrm{cm}^{-3}\right)$ & VE & Rendimento $(\%)$ & Tempo de residência $(\mathrm{s})$ \\
\hline Grãos congelados a 9,5\% & $1,49 \pm 0,024 \mathrm{~d}$ & $0,156 \pm 0,004 \mathrm{a}$ & $5,4 \pm 0,109 \mathrm{c}$ & $65,0 \pm 1,07 \mathrm{c}$ & $35,7 \pm 1,32 \mathrm{a}$ \\
Hidratados após congelamento a $11,5 \%$ & $1,59 \pm 0,017 \mathrm{c}$ & $0,134 \pm 0,003 \mathrm{~b}$ & $6,4 \pm 0,130 \mathrm{~b}$ & $75,7 \pm 1,16 \mathrm{~b}$ & $23,7 \pm 1,20 \mathrm{a}$ \\
Hidratados antes congelamento a 11,5\% & $1,63 \pm 0,011 \mathrm{~b}$ & $0,131 \pm 0,002 \mathrm{~b}$ & $6,4 \pm 0,105 \mathrm{~b}$ & $75,4 \pm 1,36 \mathrm{~b}$ & $35,0 \pm 1,12 \mathrm{a}$ \\
Hidratados após congelamento a 13,5\% & $1,62 \pm 0,018 \mathrm{bc}$ & $0,131 \pm 0,004 \mathrm{~b}$ & $6,5 \pm 0,203 \mathrm{~b}$ & $78,0 \pm 0,94 \mathrm{a}$ & $31,8 \pm 1,39 \mathrm{~b}$ \\
Hidratados antes congelamento a 13,5\% & $1,68 \pm 0,008 \mathrm{a}$ & $0,125 \pm 0,002 \mathrm{c}$ & $6,8 \pm 0,130 \mathrm{a}$ & $78,3 \pm 0,92 \mathrm{a}$ & $37,1 \pm 2,67 \mathrm{a}$ \\
\hline
\end{tabular}

${ }^{(1)}$ Médias $\_$desvio-padrão seguidas de letras iguais, na coluna, não diferem pelo teste de Tukey, a $1 \%$ de probabilidade. 
foi maior e o GD foi menor, em relação às umidades inferiores. Os grãos com 9,5\% de umidade foram os que apresentaram os menores valores de rendimento e maiores de GD.

As respostas de DMP, VE e rendimento foram crescentes com o acréscimo da umidade (Tabela 2). Por sua vez, densidade, GD e tempo de residência foram decrescentes. Observa-se que quanto maior o teor de umidade, melhor a qualidade das pipocas, com maior capacidade de expansão, maior rendimento e menor tempo de residência. Lara \& Ruales (2002) estudaram o pipocamento de $A$. caudatus com teores de umidade dos grãos entre 12 e $16 \%$, e os melhores resultados de VE foram obtidos na umidade de 12\%. Konishi et al. (2004), em pesquisas com A. hypochondriacus, mostram que o VE das pipocas, em relação à umidade do grão, tem comportamento quadrático, em que os valores de VE aumentam até um teor crítico de umidade, em torno de $16 \%$, e depois diminuem até a umidade de $30 \%$. Quando a umidade do grão é inferior à umidade ideal de pipocamento, segundo Konishi et al. (2004), a quantidade de vapor formada no interior do grão de amaranto é insuficiente para elevar a pressão a níveis adequados para um bom pipocamento e os grãos acabam sendo queimados antes do amido se expandir. Por sua vez, quando a quantidade de água é elevada, necessita-se de muita energia para a evaporação da água do interior do grão, que termina por queimá-lo antes de pipocar.

A diminuição do volume e do tamanho de floco de pipocas de milho, ocorrida além do teor crítico de umidade, pode ser explicada, segundo Shimoni et al. (2002), pela ruptura do pericarpo a uma temperatura em que a pressão no interior do núcleo é baixa, o que causa menor VE e redução do volume final da pipoca.

Os valores de densidade de pipocas de amaranto encontrados neste trabalho foram semelhantes aos apresentados por Tovar et al. (1994), que relataram valores de densidade entre $0,1 \mathrm{~g} \mathrm{~cm}^{-3}$ e $0,16 \mathrm{~g} \mathrm{~cm}^{-3}$ em pipocas de amaranto produzidas por método de

Tabela 2. Diâmetro médio ponderado, densidade, volume de expansão, rendimento, tempo de residência e percentagem de grãos descartados de pipocas de grãos Amaranthus cruentus, em função da umidade e da forma de armazenamento dos grãos $^{(1)}$.

\begin{tabular}{|c|c|c|c|c|}
\hline \multirow[t]{2}{*}{ Armazenamento } & \multicolumn{3}{|c|}{ Umidade $(\%)$} & \multirow[t]{2}{*}{ Média } \\
\hline & 9,5 & 11,5 & 13,5 & \\
\hline \multicolumn{5}{|c|}{ Diâmetro médio ponderado $(\mathrm{mm})$} \\
\hline Ambiente $\left( \pm 28^{\circ} \mathrm{C}\right)$ & $1,49 \pm 0,010 \mathrm{Ac}$ & $1,58 \pm 0,023 \mathrm{Bb}$ & $1,65 \pm 0,022 \mathrm{Ba}$ & $1,57 \pm 0,070 \mathrm{~B}$ \\
\hline Congelado $\left(-18^{\circ} \mathrm{C}\right)$ & $1,48 \pm 0,020 \mathrm{Ac}$ & $1,63 \pm 0,003 \mathrm{Ab}$ & $1,68 \pm 0,013 \mathrm{Aa}$ & $1,60 \pm 0,087 \mathrm{~A}$ \\
\hline Média & $1,48 \pm 0,0106 \mathrm{c}$ & $1,61 \pm 0,031 \mathrm{~b}$ & $1,66 \pm 0,022 \mathrm{a}$ & - \\
\hline \multicolumn{5}{|c|}{ Densidade $\left(\mathrm{g} \mathrm{cm}^{-3}\right)$} \\
\hline Ambiente $\left( \pm 28^{\circ} \mathrm{C}\right)$ & $0,157 \pm 0,003 \mathrm{Aa}$ & $0,137 \pm 0,003 \mathrm{Ab}$ & $0,126 \pm 0,003 \mathrm{Ac}$ & $0,139 \pm 0,013 \mathrm{~A}$ \\
\hline Congelado $\left(-18^{\circ} \mathrm{C}\right)$ & $0,157 \pm 0,004 \mathrm{Aa}$ & $0,132 \pm 0,002 \mathrm{Bb}$ & $0,125 \pm 0,002 \mathrm{Ac}$ & $0,138 \pm 0,014 \mathrm{~B}$ \\
\hline Média & $0,157 \pm 0,003 \mathrm{a}$ & $0,134 \pm 0,004 \mathrm{~b}$ & $0,125 \pm 0,003 \mathrm{c}$ & - \\
\hline \multicolumn{5}{|c|}{ Volume de expansão } \\
\hline Ambiente $\left( \pm 28^{\circ} \mathrm{C}\right)$ & $5,38 \pm 0,14$ & $6,20 \pm 0,14$ & $6,71 \pm 0,13$ & $6,09 \pm 0,57 \mathrm{~B}$ \\
\hline Congelado $\left(-18^{\circ} \mathrm{C}\right)$ & $5,39 \pm 0,09$ & $6,40 \pm 0,10$ & $6,80 \pm 0,13$ & $6,20 \pm 0,61 \mathrm{~A}$ \\
\hline Média & $5,38 \pm 0,11 \mathrm{c}$ & $6,29 \pm 0,16 b$ & $6,76 \pm 0,13 \mathrm{a}$ & \\
\hline \multicolumn{5}{|c|}{ Rendimento (\%) } \\
\hline Ambiente $\left( \pm 28^{\circ} \mathrm{C}\right)$ & $66,69 \pm 1,68$ & $76,53 \pm 1,31$ & $80,01 \pm 0,69$ & $74,4 \pm 5,9 \mathrm{~A}$ \\
\hline Congelado $\left(-18^{\circ} \mathrm{C}\right)$ & $65,18 \pm 1,42$ & $75,63 \pm 1,20$ & $78,38 \pm 0,85$ & $73,1 \pm 5,9 \mathrm{~B}$ \\
\hline Média & $65,90 \pm 1,70 \mathrm{c}$ & $76,1 \pm 1,30 \mathrm{~b}$ & $79,2 \pm 1,13 \mathrm{a}$ & \\
\hline Tempo de residência (s) & \multicolumn{3}{|c|}{ Tempo de residência $(\mathrm{s})$} & \\
\hline Ambiente $\left( \pm 28^{\circ} \mathrm{C}\right)$ & $37,22 \pm 2,49 \mathrm{Aa}$ & $35,00 \pm 1,73 \mathrm{Aa}$ & $31,56 \pm 1,94 \mathrm{Ab}$ & $34,59 \pm 3,10 \mathrm{~A}$ \\
\hline Congelado $\left(-18^{\circ} \mathrm{C}\right)$ & $35,89 \pm 1,17 \mathrm{Aa}$ & $32,00 \pm 1,22 \mathrm{Bb}$ & $32,56 \pm 1,67 \mathrm{Ab}$ & $33,48 \pm 2,19 \mathrm{~A}$ \\
\hline Média & $36,60 \pm 2,01 \mathrm{a}$ & $33,50 \pm 2,12 b$ & $32,10 \pm 1,83 \mathrm{~b}$ & \\
\hline Grãos descartados (\%) & \multicolumn{3}{|c|}{ Grãos descartados (\%) } & \\
\hline Ambiente $\left( \pm 28^{\circ} \mathrm{C}\right)$ & $21,70 \pm 1,81$ & $10,82 \pm 1,28$ & $6,41 \pm 1,37$ & $12,98 \pm 6,71 \mathrm{~B}$ \\
\hline Congelado $\left(-18^{\circ} \mathrm{C}\right)$ & $24,03 \pm 1,45$ & $11,59 \pm 1,24$ & $7,50 \pm 0,69$ & $14,37 \pm 7,25 \mathrm{~A}$ \\
\hline Média & $22,87 \pm 1,00 \mathrm{a}$ & $11,21 \pm 1,23 b$ & $6,96 \pm 1,19 \mathrm{c}$ & \\
\hline
\end{tabular}


ar quente ou chapa aquecida. No entanto, os valores obtidos são inferiores aos $0,178 \mathrm{~g} \mathrm{~cm}^{-3}$ encontrados por Lara \& Ruales (2002), em pipocas de A. caudatus produzidas por grãos com umidade $14 \%$, com o método de ar quente. Gamel \& Linssen (2008) encontraram densidades inferiores, em torno de $0,088 \mathrm{~g} \mathrm{~cm}^{-3} \mathrm{a}$ $0,1064 \mathrm{~g} \mathrm{~cm}^{-3}$, para pipocas de $A$. caudatuss usando método de placa aquecida.

Os melhores VE neste trabalho foram da ordem de 6,8 vezes o volume original dos grãos, obtidos com umidade dos grãos em 13,5\% (Tabela 2). Konishi et al. (2004), em dispositivo de ar quente, encontraram valores de VE entre 7 e 8,5 para $A$. hypochondriacus, sendo os maiores valores obtidos na umidade do grão em torno de $16 \%$. No entanto, a literatura apresenta valores bastante variados, pois Lara \& Ruales (2002) obtiveram VE de 5,1 para umidades de $12 \%$, a uma temperatura de $240^{\circ} \mathrm{C}$, em dispositivo de ar quente, para A. caudatus. Zapotoczny et al. (2006) encontraram valores de VE da ordem de 3,96, e utilizaram para o cálculo a razão entre a área de projeção do grão cru e a do pipocado.

Os grãos armazenados a $-18^{\circ} \mathrm{C}$ por 60 dias produziram pipocas maiores e mais leves, do que os armazenados à temperatura ambiente de $\pm 28{ }^{\circ} \mathrm{C}$, como mostram os valores de DMP, VE e densidade (Tabela 2). Esses resultados deixam evidente o efeito positivo do congelamento dos grãos no seu pipocamento, independentemente do conteúdo de umidade. No entanto, o rendimento foi maior e o GD foi menor para o armazenamento à temperatura ambiente. Um maior número de grãos armazenados à temperatura de $\pm 28^{\circ} \mathrm{C}$ conseguiu pipocar, mas a sua expansão foi menor, o que explica o fato de esses grãos apresentarem densidades maiores e DMP e VE menores. Assim, a massa de pipocas retidas na peneira $1,19 \mathrm{~mm}$ foi maior, com maior rendimento e menor descarte.

Os tempos de residência para o pipocamento dos grãos de amaranto estão coerentes com os obtidos por Lara \& Ruales (2002), que encontraram tempo de residência entre 13 e 39 s para pipocar grãos de A. caudatus com fluxo de ar quente. Esses autores alertam para o fato de que esse tempo aumenta com o aumento da carga, do conteúdo de água dos grãos e com a redução da temperatura e da velocidade do ar. O tempo de residência dos grãos, neste experimento, não sofreu influência da forma de armazenamento
(Tabela 2). No entanto, no primeiro experimento, ficou evidenciado que o momento da hidratação interfere no tempo de residência e que grãos hidratados antes do congelamento pipocam mais rápido que aqueles hidratados depois de descongelados.

A análise de variância para DMP, densidade e tempo de residência revelou que há interação significativa entre forma de armazenamento e umidade dos grãos. A análise da interação mostra que o congelamento apresentou efeito positivo sobre o DMP, apenas nos dois maiores níveis de umidade, em relação ao armazenado à temperatura ambiente (Tabela 2). É possível constatar, ainda, que a densidade das pipocas e o tempo de residência foram influenciados pela forma de armazenamento somente na umidade de $11,5 \%$. O armazenamento sob congelamento dos grãos reduziu o tempo de pipocamento, quando realizado em teores de umidade a partir de $11,5 \%$. Por sua vez, no armazenamento sob condições do ambiente, só houve redução do tempo de residência para os grãos armazenados na umidade de $13,5 \%$.

As variáveis utilizadas para avaliar as pipocas apresentaram alta correlação entre si, com exceção do tempo de residência que apresentou correlação moderada (Tabela 3). Os atributos DMP, densidade e VE, variáveis utilizadas para quantificar a capacidade de expansão dos grãos, apresentaram alta correlação entre si. A densidade e o VE foram as que apresentaram as maiores correlações com os demais atributos. Esses resultados levam a recomendar esses dois atributos como indicadores para avaliação da qualidade de pipocas de amaranto, por serem determinações rápidas e de baixo custo. De acordo com Gamel \& Linssen (2008), o volume de expansão é um critério de qualidade importante, do ponto de vista comercial, porque os compradores adquirem grãos com base na massa e vendem a pipoca pelo volume. $\mathrm{O}$ tempo de residência apresentou correlação inversa com DMP, VE, GD e rendimento, e correlação direta com a densidade, o que indica que, quanto maior o tempo para pipocar os grãos, pior será a qualidade das pipocas.

A composição química dos grãos de A. cruentus, BRS Alegria, crus e das pipocas obtidas dos grãos armazenados com $13,5 \%$ de umidade, à temperatura de $-18^{\circ} \mathrm{C}$, tratamento que resultou em pipocas com maior expansão, revelou valores diferentes de proteínas, lipídeos e fibras solúveis e insolúveis (Tabela 4). Os teores de lipídeos encontrados nas pipocas foram 
Tabela 3. Correlação entre as variáveis utilizadas na avaliação de pipocas de Amaranthus Cruentus.

\begin{tabular}{|c|c|c|c|c|c|}
\hline Variáveis & $\mathrm{DMP}(\mathrm{mm})$ & Densidade $\left(\mathrm{g} / \mathrm{cm}^{3}\right)$ & Volume de expansão & Rendimento (\%) & Tempo de residência (s) \\
\hline Densidade & $-0,97 * *$ & - & - & - & - \\
\hline Volume de expansão & $0,97^{* *}$ & $-1,00 * *$ & - & - & - \\
\hline Rendimento & $0,92 * *$ & $-0,94 * *$ & $0,94 * *$ & - & - \\
\hline Tempo de residência & $-0,74 * *$ & $0,75 * *$ & $-0,75 * *$ & $-0,66^{* *}$ & - \\
\hline Grãos descartados (\%) & $-0,93 * *$ & $0,96 * *$ & $-0,95 * *$ & $-0,98 * *$ & $-0,64 * *$ \\
\hline
\end{tabular}

DMP, diâmetro médio ponderado; **Significativo a $1 \%$ de probabilidade.

Tabela 4. Composição química (percentagem em base seca) de grãos Amaranthus cruentus congelados a 13,5\% de umidade, crus e pipocados ${ }^{(1)}$.

\begin{tabular}{|c|c|c|c|c|c|c|c|}
\hline \multirow[t]{2}{*}{ Grãos } & \multirow[t]{2}{*}{ Cinzas } & \multirow[t]{2}{*}{ Proteínas } & \multirow[t]{2}{*}{ Lipídeos } & \multirow[t]{2}{*}{ Carboidratos } & \multicolumn{3}{|c|}{ Fibras } \\
\hline & & & & & Insolúvel & Solúvel & Total \\
\hline Crus & $2,14 \pm 0,06 \mathrm{a}$ & $15,27 \pm 0,03 \mathrm{a}$ & $6,43 \pm 0,03 b$ & $76,16 \pm 0,10 \mathrm{a}$ & $8,27 \pm 0,05 a$ & $1,27 \pm 0,04 b$ & $9,54 \pm 0,10 \mathrm{a}$ \\
\hline Pipocados & $2,20 \pm 0,03 \mathrm{a}$ & $14,49 \pm 0,01 \mathrm{~b}$ & $7,54 \pm 0,08 \mathrm{a}$ & $75,77 \pm 0,08 \mathrm{~b}$ & $7,47 \pm 0,16 b$ & $1,98 \pm 0,08 \mathrm{a}$ & $9,45 \pm 0,23 \mathrm{a}$ \\
\hline
\end{tabular}

${ }^{(1)}$ Médias $\_$desvio-padrão seguidas de letras iguais, nas colunas, não diferem pelo teste t, a $5 \%$ de probabilidade.

superiores aos encontrados nos grãos crus. Nos grãos de amaranto, a matriz embrionária contém os lipídeos nas formas livre ou complexados, conforme Irving et al. (1981), o que pode tornar difícil a sua extração pelo método Soxhlet de extração utilizado neste trabalho. No entanto, o pipocamento pode liberar o lipídeo complexado e torná-lo mais fácil de ser extraído pelo solvente que, nesse caso, foi o éter de petróleo. Dessa forma, a maior quantidade de lipídeos encontrada pode estar associada ao método de extração utilizado.

As reduções dos conteúdos de proteínas e de fibras insolúveis nas pipocas podem estar relacionadas às perdas de frações da casca do grão durante a expansão pois, conforme Bucaro Segura \& Bressani (2002), a maioria das proteínas estão distribuídas no germe e na casca do grão, e apenas uma pequena parte encontra-se no perisperma. $\mathrm{O}$ aumento das fibras solúveis provavelmente está associado às condições severas do tratamento térmico utilizado para a obtenção das pipocas de grãos de amaranto, pois, segundo Repo-Carrasco-Valencia et al. (2009), altas temperaturas podem quebrar as ligações das cadeias de polissacarídeos da parede celular em partículas mais solúveis.

As pipocas de amaranto, apesar das perdas de nutrientes ocorridas durante o processamento, podem ser consideradas uma fonte de nutrientes superior à pipoca obtida de outros cereais, e é uma forma simples e atrativa de consumo e de introdução deste grão na alimentação de crianças e adultos.

\section{Conclusões}

1. O congelamento favorece o pipocamento do grão amaranto.

2. A hidratação de grãos a 13,5\% de umidade propicia melhor expansão e maior rendimento.

3. A produção de pipocas, pelo método de chapa aquecida, reduz os teores de proteínas e fibras insolúveis e aumenta os de lipídeos e fibras solúveis, em comparação aos grãos crus.

4. $\mathrm{O}$ congelamento dos grãos a $-18^{\circ} \mathrm{C}$ e hidratação a $13,5 \%$ favorecem o pipocamento de Amaranthus cruentus e produz pipocas de melhor qualidade.

\section{Referências}

AACC INTERNATIONAL. Approved methods of analysis: method 32-07.01: soluble, insoluble, and total dietary fiber in foods and food products. $11^{\text {th }} \mathrm{ed}$. St Paul: AACC International, 1999.

AMAYA-FARFAN, J.; MARCÍLIO, R.; SPEHAR, C.R. Deveria o Brasil investir em novos grãos para sua alimentação? A proposta do amaranto (Amaranthus sp.). Segurança Alimentar e Nutricional, V.12, p.47-56, 2005.

AOAC INTERNATIONAL. Official methods of analysis of the AOAC International. $16^{\text {th }}$ ed. Arlington: AOAC International, 1998. 1298p.

BERGHOFER, E.; SCHOENLECHNER, R. Grain amaranth. In: BELTON, P.S.; TAYLOR, J.R.N. Pseudocereals and less common cereals: grain properties and utilization potential. New York: Springer, 2002. p.219-260.

BODROZA-SOLAROV, M.; FILIPCEV, B.; KEVRESAN, Z.; MANDIC, A.; SIMURINA, O. Quality of bread supplemented with popped Amaranthus cruentus grain. Journal of Food Process Engineering, v.31, p.602-618, 2008. 
BRESSANI, R.; SÁNCHEZ-MARROQUÍN, A.; MORALES, E. Chemical composition of grain amaranth cultivars and effects of processing on their nutritional quality. Food Reviews International, v.8, p.23-49, 1992.

BUCARO SEGURA, M.E.B.; BRESSANI, R. Distribución de la proteína em fracciones físicas de La molienda y tamizado del grano de amaranto. Archivos Latinoamericanos de Nutrición, v.52, p.167-171, 2002.

CAPRILES, V.D.; COELHO, K.D.; MATIAS, A.C.G.; ARÊAS, J.A.G. Efeito da adição de amaranto na composição e na aceitabilidade do biscoito tipo coockie e do pão de forma. Alimentos e Nutrição, v.17, p.269-274, 2006.

CORRÊA, J.C. Efeito de sistemas de cultivo na estabilidade de agregados de um Latossolo Vermelho-Amarelo em Querência, MT. Pesquisa Agropecuária Brasileira, v.37, p.203-209, 2002.

COSTA, D.M.A. da; BORGES, A.S. Avaliação da produção agrícola do amaranto (Amaranthus hypochondriacus). Holos, ano 21, p.97-111, 2005.

DAMODARAN, S.; PARKIN, K.L.; FENNEMA, O.R. Fennema's food chemistry. $4^{\text {th }}$ ed. Boca Raton: CRC, 2008. 1144p.

DELOST-LEWIS, K.; LORENZ, K.; TRIBELHORN, R. Puffing quality of experimental varieties of proso millets (Panicum miliaceum). Cereal Chemistry, v.69, p.359-362, 1992.

FERREIRA, T.A.P.C.; MATIAS, A.C.G.; ARÊAS, J.A.G. Características nutricionais e funcionais do amaranto (Amaranthus spp.). Nutrire, v.32, p.91-116, 2007.

GAMEL, T.H.; LINSSEN, J.P.H. Flavor compounds of popped amaranth seeds. Journal of Food Processing and Preservation, v.32 p.656-668, 2008.

INSTITUTO ADOLFO LUTZ. Normas analíticas do Instituto Adolfo Lutz: métodos químicos e físicos para análises de alimentos. 4.ed. Brasília: Anvisa, 2005. 1018p.

IRVING, D.W.; BETSCHART, A.A.; SAUNDERS, R.M. Morphological studies on Amaranthus cruentus. Journal of Food Science, v.46, p.1170-1174. 1981.

KONISHI, Y.; IYOTA, H.; YOSHIDA, K.; MORITANI, J.; INOUE, T.; NISHIMURA, N.; NOMURA, T. Effect of moisture content on the expansion volume of popped amaranth seeds by hot air and superheated steam using a fluidized bed system. Bioscience, Biotechnology, and Biochemistry, v.68, p.2186-2189, 2004.

LARA, N.; RUALES, J. Popping of amaranth grain (Amaranthus caudatus) and its effect on the functional, nutritional and sensory properties. Journal of the Science of Food and Agriculture, v.82, p.797-805, 2002.
MARCILIO, R.; AMAYA-FARFAN, J.; SILVA, M.A.A.P. da; SPEHAR, C.R. Avaliação da farinha de amaranto na elaboração de biscoito sem glúten do tipo coockie. Revista Brasileira de Tecnologia de Alimentos, v.8, p.175-181, 2005.

MENDONÇA, S.; SALDIVA, P.H.; CRUZ, R.J.; ARÊAS, J.A.G. Amaranth protein presents cholesterol-lowering effects. Food Chemistry, v.116, p.738-742, 2009.

MINITAB. Minitab: software for quality improvement. Versão 13.1. Belo Horizonte: Minitab, 2005.

REPO-CARRASCO-VALENCIA, R.; PEÑA, J.; KALLIO, H.; SALMINEM, S. Dietary fiber and other functional components in two varieties of crude and extruded kiwicha (Amaranthus caudatus). Journal of Cereal Science, v.49, p.219-224, 2009.

SHIMONI, E.; DIRKS, E.M.; LABUZA, T.P. The relation between final popped volume of popcorn and thermal-physical parameters. Lebensmittel-Wissenschaft Und Technology, v.35, p.93-98, 2002.

SINGHAL, R.S.; KULKARNI, P.R. Puffing effects on functional properties of Amaranthus paniculatus (Rajgeera) seed flour. Journal of Food Science, v.56, p.1121-1122, 1991.

SPEHAR, C.R.; TEIXEIRA, D.L. Caracterização agronômica de acessos em três espécies de amaranto no bioma cerrado. Planaltina: Embrapa Cerrados, 2004. 21p. (Embrapa Cerrados. Boletim de pesquisa e desenvolvimento, 131).

SPEHAR, C.R.; TEIXEIRA, D.L.; LARA CABEZAS, W.A.R.L.; ERASMO, E.A.L. Amaranto BRS Alegria: alternativa para diversificar os sistemas de produção. Pesquisa Agropecuária Brasileira, v.38, p.659-663, 2003.

TIKEKAR, R.V.; KARWE, M.V. Development of a continuous method for puffing amaranth (Amaranthus spp.) seeds. Journal of Food Process Engineering, v.32, p.265-277, 2009.

TOSI, E.; RÉ, E.D.; MASCIARELLI, R.; CIAPPINI, M. Aplicatión de la técnica de lecho fluidizado a la producctión de rosetas de amaranto. Alimentaria, n.269, p.45-47, 1996.

TOVAR, L.R.; VALDIVIA, M.A.; BRITO, E. Popping amaranth, state of the art. In: PAREDES-LÓPEZ, O. (Ed). Amaranth: biology, chemistry, and technology. Boca Raton: CRC, 1994. p.143-154.

ZAPOTOCZNY, P.; MARKOWSKI, M.; MAJEWSKA, K.; RATAJSKI, A.; KONOPKO, H. Effects of temperature on the physical, functional, and mechanical characteristics of hot-air-puffed amaranth seeds. Journal of Food Engineering, v.76, p.469-476, 2006.

Recebido em 9 de março de 2010 e aprovado em 23 de junho de 2010

Pesq. agropec. bras., Brasília, v.45, n.8, p.917-924, ago. 2010 